\title{
IDENTIFICAÇÃO DA ADVECÇÃO DE AR QUENTE ATRAVÉS DA ANÁLISE DE DADOS DE SATÉLITES
}

\author{
N. Fedorova \& L. Bakst
}

\begin{abstract}
Neste trabalho foram encontradas duas características para a identificação da advecção de ar quente: a curvatura anticiclônica da massa de nuvens e a presença de uma quantidade maior de nuvens Cirrus na fronteira desta massa. Estes resultados foram obtidos através da análise integrada de dados de satélites e de dados sinóticos convencionais. As nuvens observadas localizavam-se na periferia norte e noroeste do anticiclone, no cavado de um ciclone, ou no campo de pressão baixa e difusa que, geralmente, é apresentado como sendo uma linha de instabilidade nas cartas sinóticas. Em algumas situações, forma-se um ciclone, em outras, ocorre o processo de frontogênese ou a regeneração de um ciclone velho. Os dados de satélite permitiram a identificação e determinação das regiões com advecção de ar quente com uma antecedência de 24 a 48 horas em relação ao dados sinóticos.
\end{abstract}

Palavras-chave: Carta sinótica; Imagens de satélite; Advecção de ar quente.

IDENTIFICATION OF WARM AIR ADVECTION ON SATELLITE DATA- The paper presents a study of cloudiness having the typical structure: the anticyclone curvature of the cloud's mass and a large quantity of cirrus clouds on the cloudiness' border. The integrated analysis of conventional and satellite data has shown that this cloudiness structure is observed in synoptic situations of warm air advection. This cloudiness was localized in the northerly and northwesterly periphery of the anticyclone, in the trough of the cyclone, or in the diffuse pressure field, generally presented as lines of instability in synoptic maps. Sometimes, as a result of the warm advection, it is observed frontogenesis, cyclogenesis or the regeneration of the old cyclone. The satellite data enables the discrimination of warm air advection regions earlier (24-48 h) than the synoptic maps.

Key words: Synoptic map; Satellite images; Thermal advection.

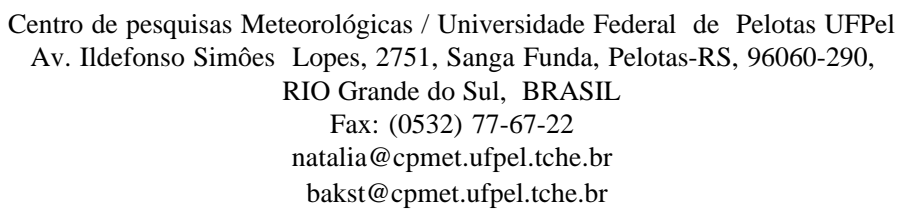




\section{INTRODUÇÃO}

A advecção de ar quente produz uma intensa modificação do tempo, o que torna a identificação de regiões com advecção de ar quente muito importante para a análise da situação sinótica, da zona frontal, das condições de frontogênese e ciclogênese. Por isso, o seu estudo possibilita uma melhor compreensão dos processos sinóticos e, principalmente, fornece o suporte necessário às atividades de previsão meteorológica operacional.

As nuvens são o resultado de diversos processos observados na atmosfera, incluindo a advecção de ar quente e, por isso, a presença de nuvens ser um indicador da ocorrência deste fenômeno. Os tipos e a distribuição horizontal das nuvens são bem identificados através dos dados de satélite, o que os tornam úteis para a análise dos processos de advecção térmica.

Vários estudos indicam que os dados de satélite possibilitam a identificação de regiões com advecção de ar frio (Rao et al., 1990 ; Ccoyllo \& Silva Dias, 1996; Carlson, 1980; Vetlov \& Veltichev, 1982; Fedorova \& Bakst,1991; Bakst \& Fedorova, 1991). Todavia, ainda não existe um método para a identificação da advecção de ar quente, através de dados de satélite.

Neste trabalho é apresentado um método para a identificação de advecção de ar quente usando somente imagens de satélite. A importância deste estudo se deve ao fato de que, muitas vezes, o meteorologista não dispõe de dados convencionais necessários à elaboração das previsões de tempo. Assim, é importante que ele conte com métodos alternativos para que possa prever a advecção de ar quente utilizando, por exemplo, as imagens de satélite. Além disso, um dos objetivos deste trabalho é proporcionar um melhor entendimento de processos meteorológicos através da análise de imagens de satélite. Outro objetivo é mostrar os processos sinóticos que ocorrem sobre a América do Sul, decorrentes da advecção de ar quente.

\section{DADOS E PROCEDIMENTOS}

No presente estudo, foram utilizados dados dos satélites geoestacionários METEOSAT e GOES, e os seguintes dados sinóticos convencionais: mapas sinóticos, gráficos do termógrafo da estação meteorológica do $8^{-}$ DISME (Porto Alegre - RS) e da estação agroclimatológica de Pelotas - RS (convênio EMBRAPA/UFPel), mapas de temperatura de $700 \mathrm{hPa}$ das 00:00 TMG do National Center for Environment Prediction (NCEP). O período escolhido compreende os meses de agosto a dezembro de 1995 e os meses de janeiro a março de 1996. Durante este período foram observados, nas imagens dos satélites que cobrem a região da América do Sul, doze processos com massas de nuvens com curvatura anticiclônica. Cada processo durou, aproximadamente, dois a três dias e foi analisado durante todo este período. Nestes dias foi calculada a modificação local de temperatura $T$ devido à advecção geostrófica:

$$
\left(\frac{\partial T}{\partial t}\right)_{\text {advg }}=-\frac{g}{f}\left(\frac{\partial H}{\partial x} \frac{\partial T}{\partial y}-\frac{\partial H}{\partial y} \frac{\partial T}{\partial x}\right)
$$

onde $H$ é a altura geopotencial e $f$ é o parâmetro de Coriolis.

A análise paralela dos dados de satélite e sinóticos convencionais permitem a identificação de sinais da ocorrência de advecção de ar quente nas imagens de satélite, com base nas observações dos dados convencionais. Dividiram-se os processos sinóticos resultantes da advecção de ar quente em quatro grupos, os quais são discutidos e amplamente ilustrados.

\section{RESULTADOS}

Massas de nuvens com uma configuração característica nas imagens dos satélites ( curvatura anticiclônica e a presença de uma quantidade maior de nuvens Cirrus na fronteira da massa de nuvens ) são os sinais que identificam regiões com advecção de ar quente.

A seguir, são apresentados os quatro grupos de processos sinóticos típicos que ocorrem como conseqüência da advecção de ar quente.

\section{Frontogênese}

Em situações em que as imagens de satélite mostram sinais através dos quais pode-se identificar a ocorrência de advecção de ar quente, os mapas sinóticos denotam a presença de linhas de instabilidade no campo de pressão baixa mal organizado.

A advecção de ar quente acarreta um aumento do gradiente de temperatura e, conseqüentemente, contribui para a frontogênese e, também, para a intensificação da corrente de jato (Bluestein, 1993). Esta intensificação pode ser observada nas imagens de satélite pela presença de nuvens cirriformes com curvatura anticiclônica.

Como conseqüência da advecção quente, ocorre a elevação da temperatura próximo à superfície, nas partes central e norte da massa de nuvens. Somente depois de 24 a 48 horas da ocorrência da advecção de ar quente nas imagens de satélite é que as cartas sinóticas mostram a presença de frontogênese, através da formação de uma pequena região com pressão baixa, com uma isóbara fechada.

A seguir, apresenta-se um exemplo do processo exposto acima, para o período de 10 a12 de agosto de 1995. A análise das Figs. 1 a 5 demonstra a seguinte evolução:

-10 de agosto: a periferia da frente fria do ciclone, que foi observado sobre o oceano Atlântico encontra-se sobre a costa leste do Brasil, aproximadamente ao longo da latitude $25^{\circ} \mathrm{S}$. A imagem de satélite mostra 


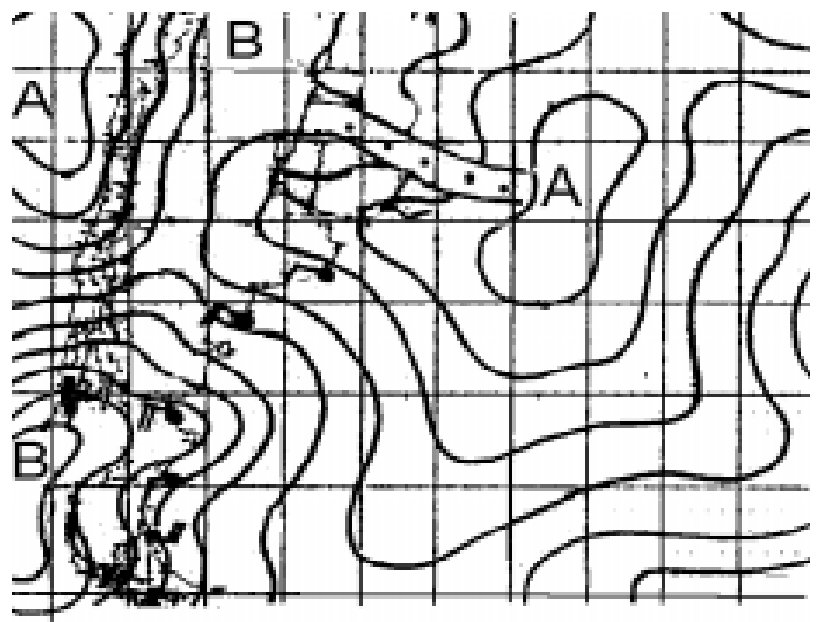

Figura 1- Mapa de pressão à superfície do dia 11 de agosto de 1995.

Figure 1- Surface pressure map for 11 August 1995.

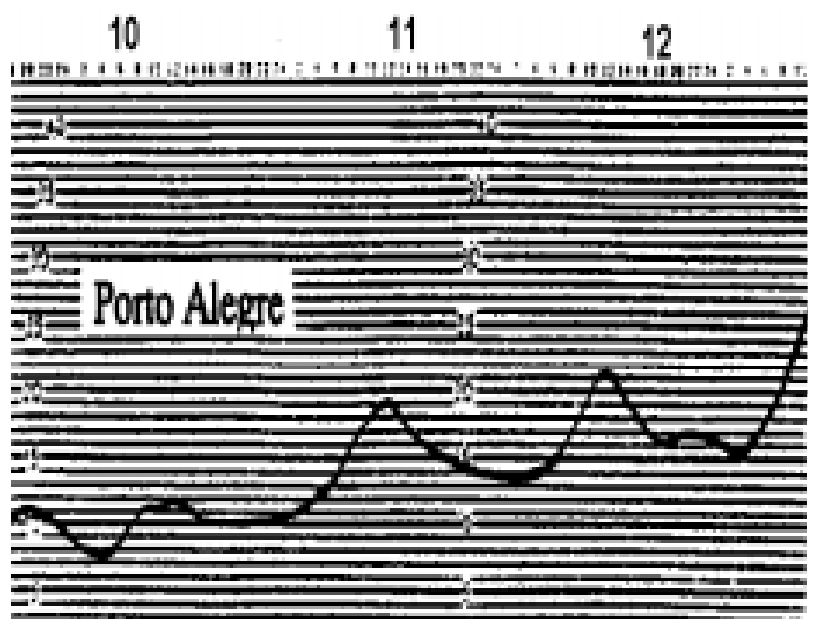

Figura 2- Gráficos da mudança de temperatura dos dias 10, 11, 12 de agosto de 1995.

Figure 2- Surface temperature variation for 10, 11, 12 August 1995.

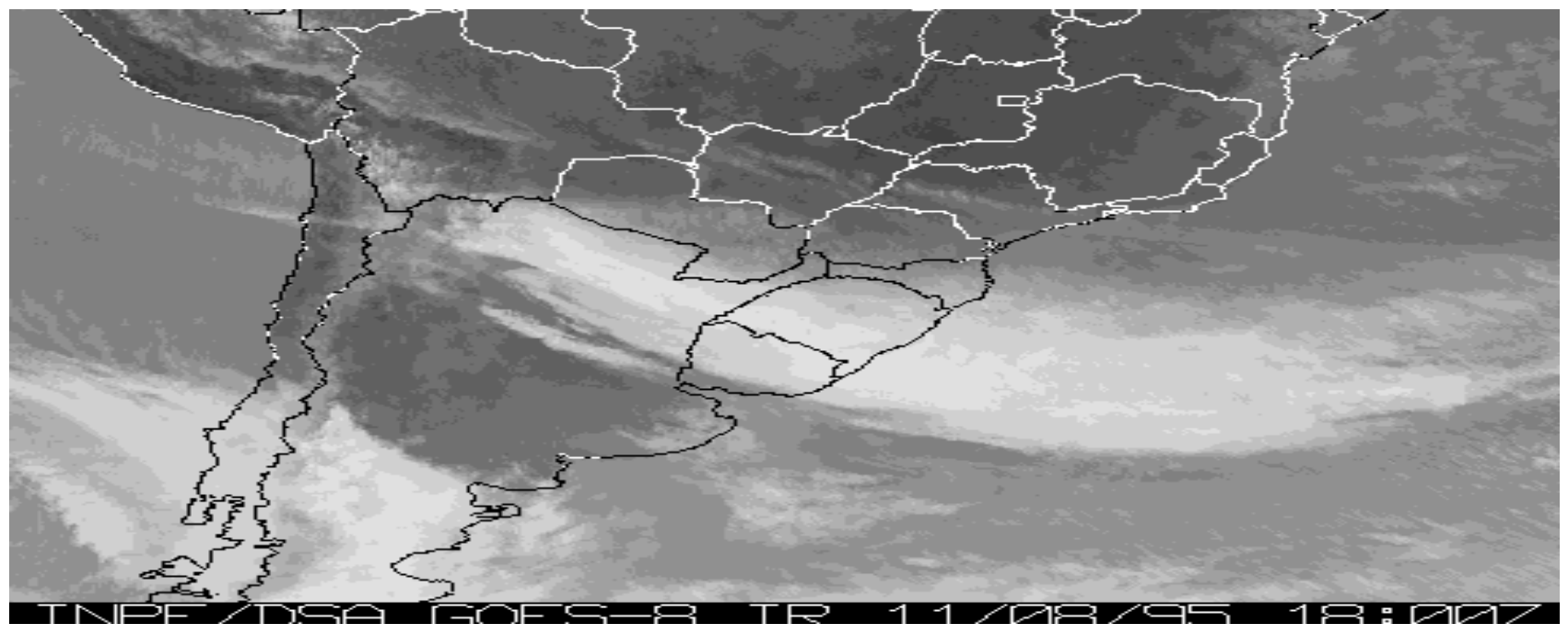

Figura 3- Processo sinótico do dia 11 de agosto de 1995 na imagen de satélite GOES-8.

Figure 3- Synoptic process for 11 August 1995 on GOES-8 image.

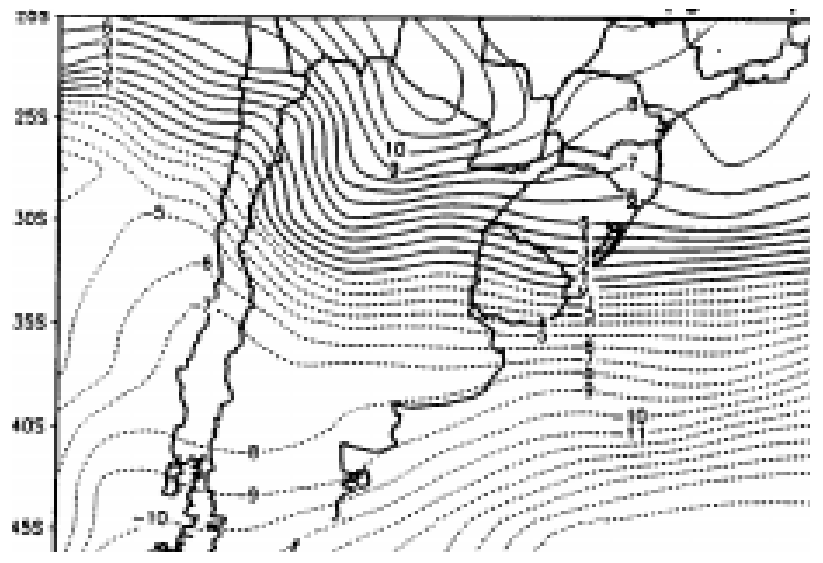

Figura 4- Mapa de temperatura do ar $\left({ }^{\circ} \mathrm{C}\right)$ no nível de 700 $\mathrm{hPa}$ do dia 11 de agosto de 1995.

Figure 4- Air temperature map $\left({ }^{\circ} \mathrm{C}\right)$ at the level $700 \mathrm{hPa}$ for 11 August 1995.

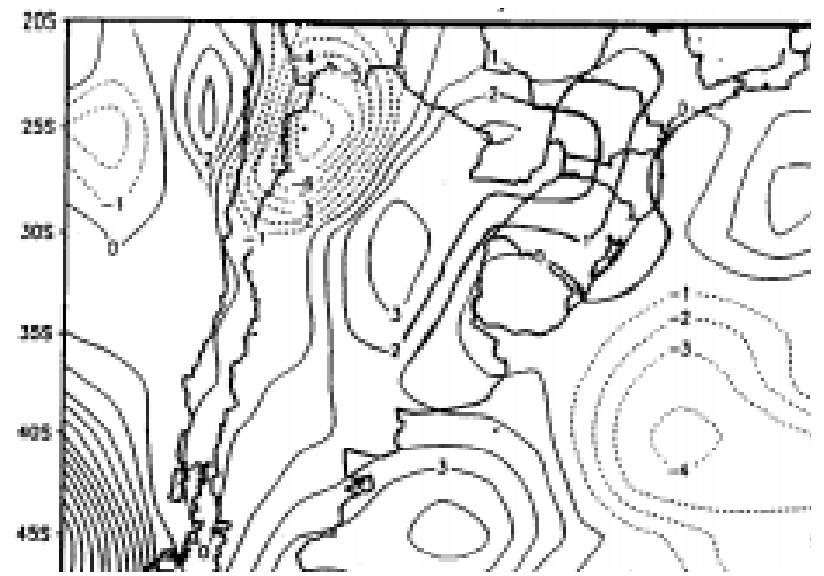

Figura 5- Mapa de advecção de temperatura do $\operatorname{ar}\left({ }^{\circ} \mathrm{C} / 12\right.$ horas $)$ no nível de $700 \mathrm{hPa}$ do dia 11 de agosto de 1995.

Figure 5- Thermal advection map $\left({ }^{\circ} \mathrm{C} / 12\right.$ hours $)$ at the level $700 \mathrm{hPa}$ for 11 August 1995. 
que a frente fria termina sobre o oceano e sobre a costa leste existe nova massa de nuvens. Na carta de pressão à superfície, permanece o campo de pressão baixa e difusa na parte norte desta massa de nuvens; na parte sul dela, fica o cavado fraco e a periferia norte do anticiclone.

-11 de agosto: esta massa de nuvens caracterizase pela curvatura anticiclônica e pela cor branca e intensa, para quase toda a massa de nuvens. No lado frio da fronteira da massa de nuvens é observada a corrente de jato nos dados de satélite. No mapa de pressão à superfície é observado um cavado fraco, uma linha de instabilidade, e o giro do vento.

-12 de agosto: esta massa de nuvens desloca-se para o oceano e o mapa de pressão à superfície mostra uma pequena região com pressão baixa ( uma isóbara fechada ) com uma zona frontal.

Em Pelotas (RS), a temperatura média diária do ar próximo à superfície, de $10 \mathrm{a} 12$ de agosto, aumentou em $6,5^{\circ} \mathrm{C}$ e a temperatura máxima aumentou em 6,6 ${ }^{\circ} \mathrm{C}$; em Porto Alegre (RS), a temperatura máxima aumentou em $7,4^{\circ} \mathrm{C}$ e a temperatura mínima em $5,8^{\circ} \mathrm{C}$; o aumento mais intenso foi observado de 11 a 12 de agosto. Os mapas de temperatura em $700 \mathrm{hPa}$ apresentaram a elevação da mesma sobre as regiões norte da Argentina e Sul do Brasil; também ali formaram-se regiões com advecção de ar quente.

\section{Regeneração de ciclone}

Neste tipo de processo, as imagens de satélites mostram uma massa de nuvens com curvatura anticiclônica e nos mapas sinóticos localiza-se uma linha de instabilidade no cavado do ciclone térmico. Diferentemente das situações descritas no item anterior, a linha da fronteira da massa de nuvens não é nítida e a corrente de jato não é observada neste local, pelos

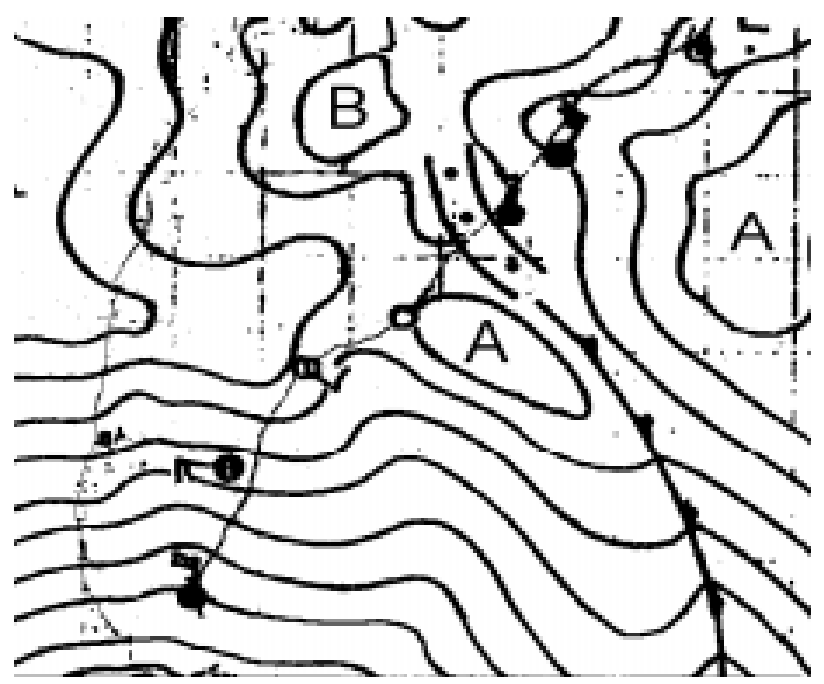

Figura 6- Mapa de pressão à superfície do dia 22 de novembro de 1995.

Figure 6- Surface pressure map for 22 November 1995.

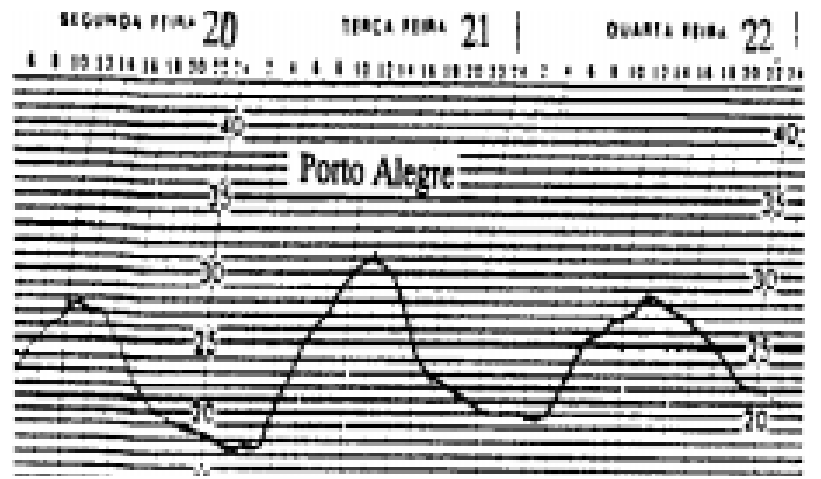

Figura 7- Gráficos da mudança de temperatura dos dias 21, 22 de novembro de 1995.

Figure 7- Surface temperature variation for 21, 22 November 1995.

dados de satélite. Devido à formação da corrente de ar quente, ocorre a regeneração do ciclone velho e da zona frontal.

Apresenta-se, a seguir, um exemplo do processo descrito acima, para o período de 21 a 22 de novembro 1995. As Figs. 6 a 10 mostram uma situação que é muito parecida com aquela descrita no ítem anterior. Todavia, de 21 a 22 de novembro ocorreu a união das massas de nuvens da periferia da frente fria com a massa de nuvens de curvatura anticiclônica do cavado do ciclone térmico. Nos mapas sinóticos, a massa de nuvens de curvatura anticiclônica é interpretada como uma linha de instabilidade.

Os mapas de temperatura mostraram a corrente de ar quente sobre o leste da Argentina, Uruguai, Rio Grande do Sul e oeste do Oceano Atlântico. Os mapas de advecção apresentaram advecção de ar quente sobre o RS e o leste do Oceano Atlântico. No período de 20 a 21 de novembro, a temperatura média diária do ar próximo à superfície em Pelotas aumentou em $1,3^{\circ} \mathrm{C}$, a temperatura máxima aumentou em $2,0^{\circ} \mathrm{C}$; em Porto Alegre, a temperatura máxima aumentou em $3,0^{\circ} \mathrm{C}$ e a temperatura mínima em $1,2^{\circ} \mathrm{C}$. Durante este processo estas cidades ficaram na periferia leste da massa de nuvens de curvatura anticiclônica.

A união da massa de nuvens de curvatura anticiclônica com a periferia da frente fria mostra que a frente alimenta-se do ar quente e por isso ocorre o processo de regeneração do ciclone no sul do Oceano Atlântico. A massa de nuvens de curvatura anticiclônica sobre o norte da Argentina dirige o processo da regeneração do ciclone no sul do Oceano Atlântico e por este processo formou o tempo em grande parte da América do Sul.

\section{Processos de mesoescala}

Neste tipo de processo, decorrente da advecção de ar quente em mesoescala, as imagens dos satélites mostram uma massa de nuvens de curvatura anticiclônica desta escala espacial; nos mapas sinóticos 


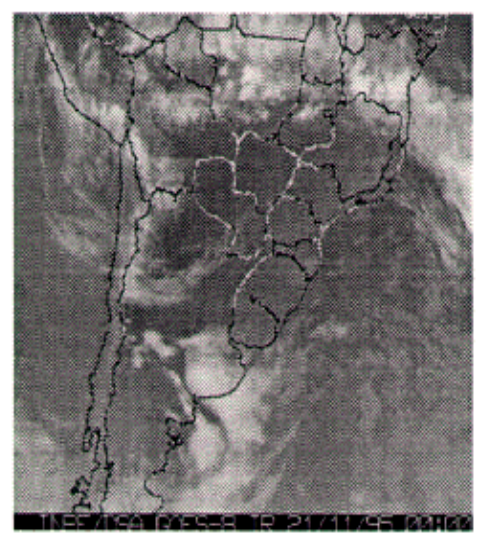

A. $11.2100 \mathrm{~h}$

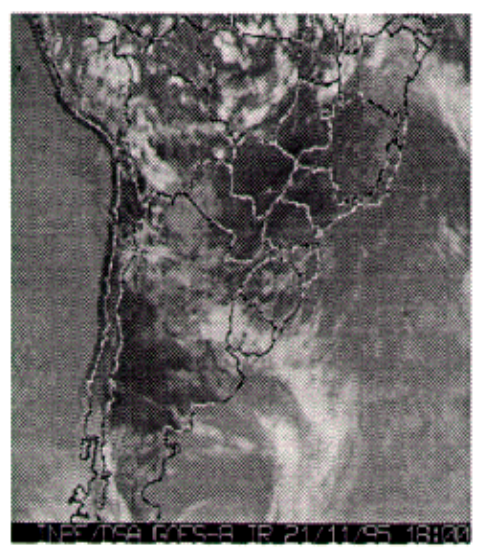

D. $11.2118 \mathrm{~h}$

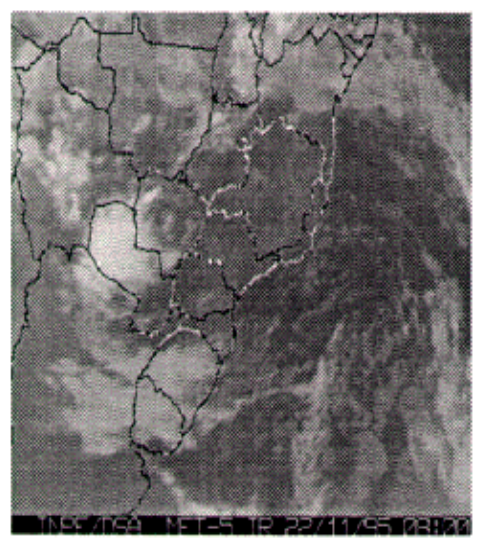

G. $11.2208 \mathrm{~h}$

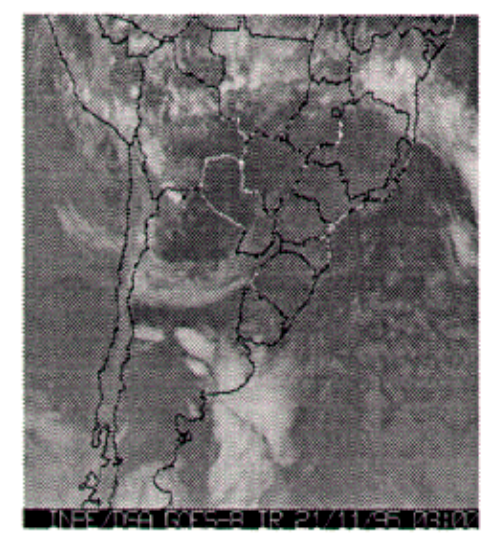

B. $11.2103 \mathrm{~h}$

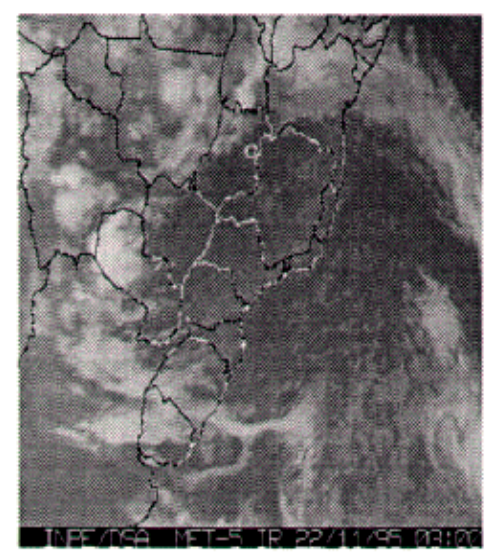

E. $11.2203 \mathrm{~h}$

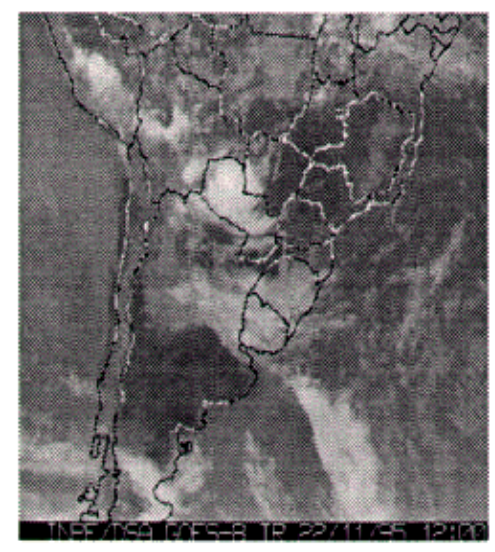

H. $11.2212 \mathrm{~h}$

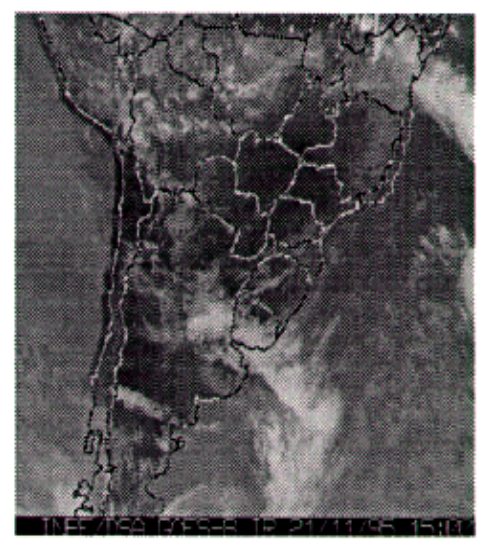

C. $11.2115 \mathrm{~h}$

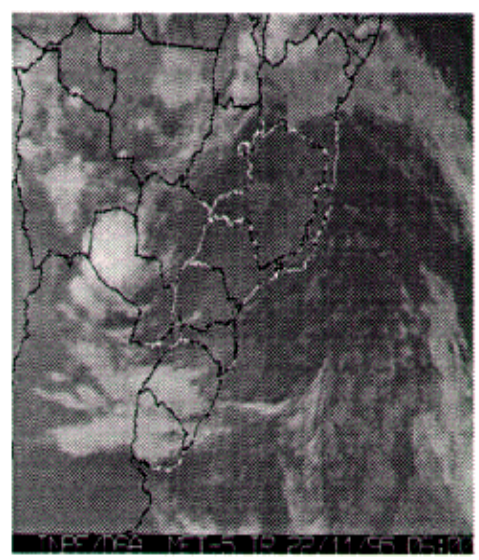

F. $11.2206 \mathrm{~h}$

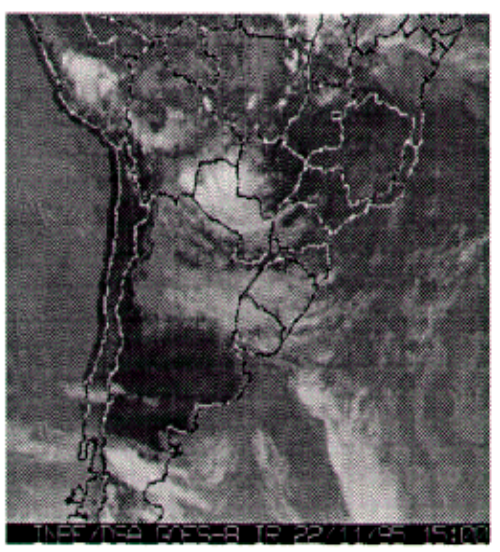

I. $11.2215 \mathrm{~h}$

Figura 8- Processo sinótico dos dias 21, 22 de novembro de 1995 nas imagens de satélite GOES-8.

Figure 8- Synoptic process for 21, 22 November 1995 on GOES-8 images. 


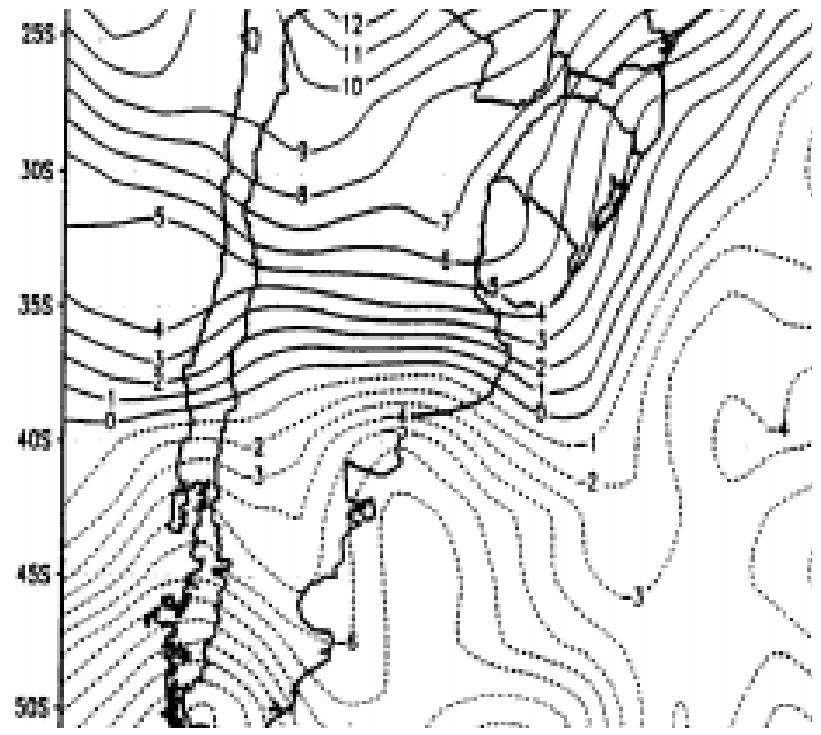

Figura 9- Mapa de temperatura do ar $\left({ }^{\circ} \mathrm{C}\right)$ no nível de $700 \mathrm{hPa}$ do dia 22 de novembro de 1995.

Figure 9- Air temperature map $\left({ }^{\circ} \mathrm{C}\right)$ at the level $700 \mathrm{hPa}$ for 22 November.

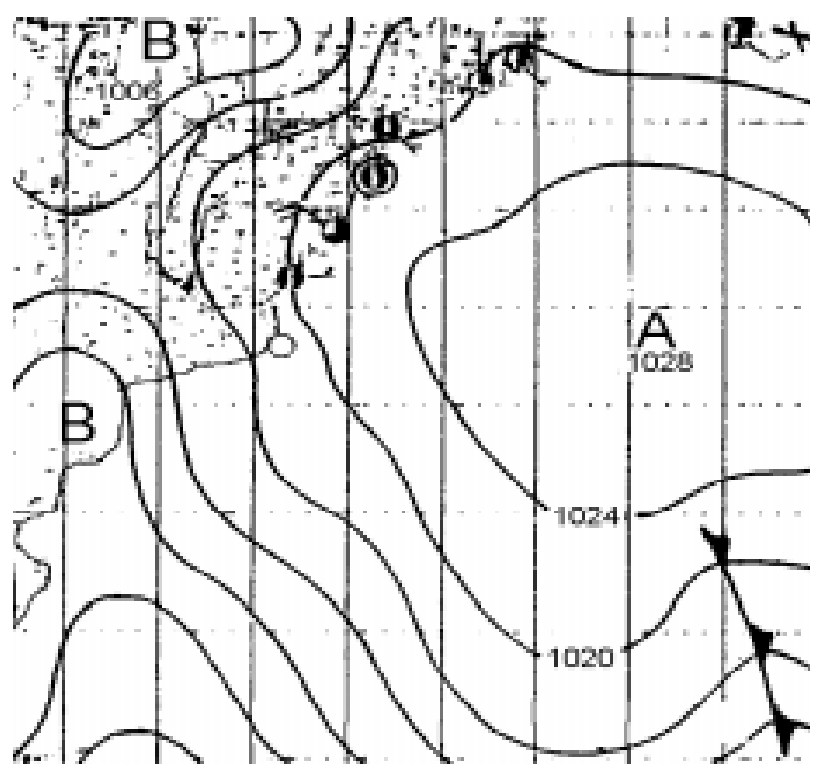

Figura 11- Mapa de pressão à superfície do dia 15 de fevereiro de 1996.

Figure 11- Surface pressure map for 15 February 1996.

localiza-se a periferia norte e noroeste do anticiclone. Sobre a superfície, é observado um aumento de temperatura.

A seguir, apresenta-se um exemplo da situação descrita acima, para o período de 14 a 15 de fevereiro de 1996 (Figs. 11 a 15 ). Nestes dias foi observada uma massa de nuvens de mesoescala de curvatura anticiclônica, que deslocou-se sobre as regiões norte da Argentina, Uruguai e Sul do Rio Grande do Sul na direção oeste- leste. A carta de pressão à superfície mostrou que esta massa permaneceu na periferia noroeste do anticiclone subtropical.

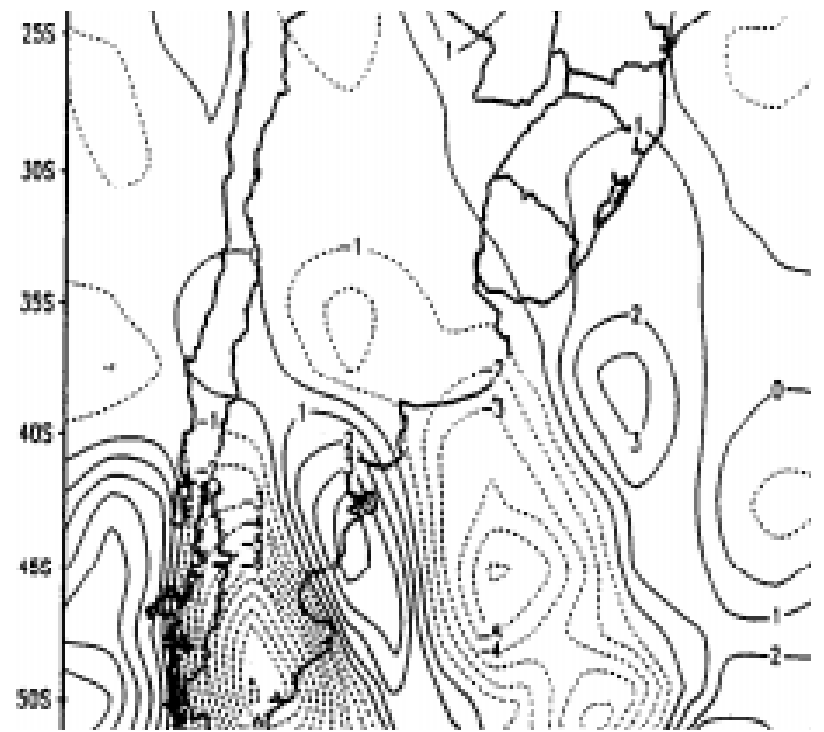

Figura 10- Mapa de advecção de temperatura do $\operatorname{ar}\left({ }^{\circ} \mathrm{C} / 12\right.$ horas) no nível de $700 \mathrm{hPa}$ do dia 22 de novembro 1995.

Figure 10- Thermal advection map $\left({ }^{\circ} \mathrm{C} / 12\right.$ hours $)$ at the level 700 hPa for 22 November 1995.

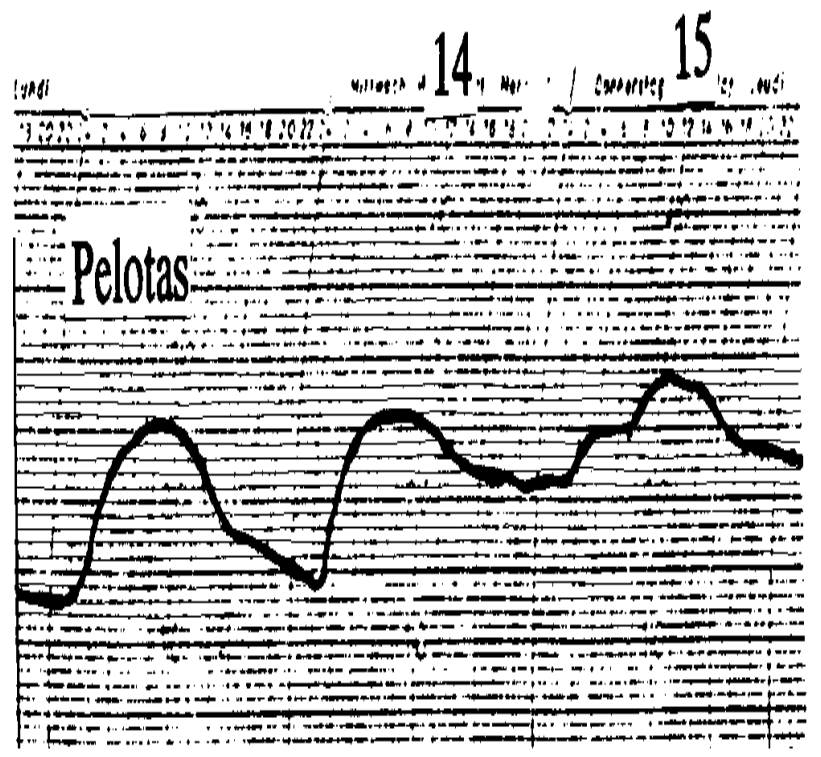

Figura 12- Gráficos da mudança de temperatura dos dias 14 e 15 de fevereiro de 1996.

Figure 12- Surface temperature variation for 14 and 15 February 1996.

Os dados sinóticos marcaram a elevação da temperatura à superfície: em Pelotas, no período de 13 a 15 de fevereiro, a temperatura mínima aumentou em $8,4^{\circ} \mathrm{C}$, a temperatura máxima aumentou em $2,4^{\circ} \mathrm{C}$. O mapa de temperatura do dia 15 de fevereiro mostra que, sob esta massa de nuvens nas partes norte, noroeste e central do RS, a temperatura foi mais alta e foi observada uma região de mesoescala com advecção de ar quente. Todos estes dados mostram que, sob a massa de nuvens de mesoescala de curvatura anticiclônica, é observada a elevação da temperatura nesta região. 


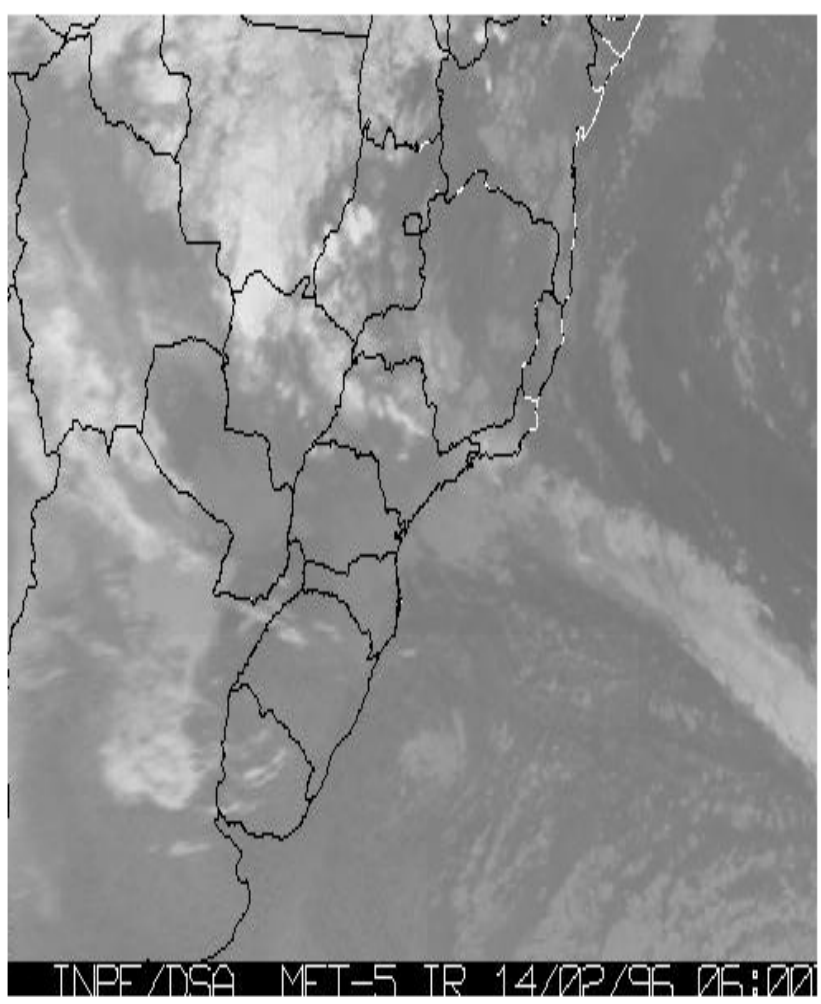

a)

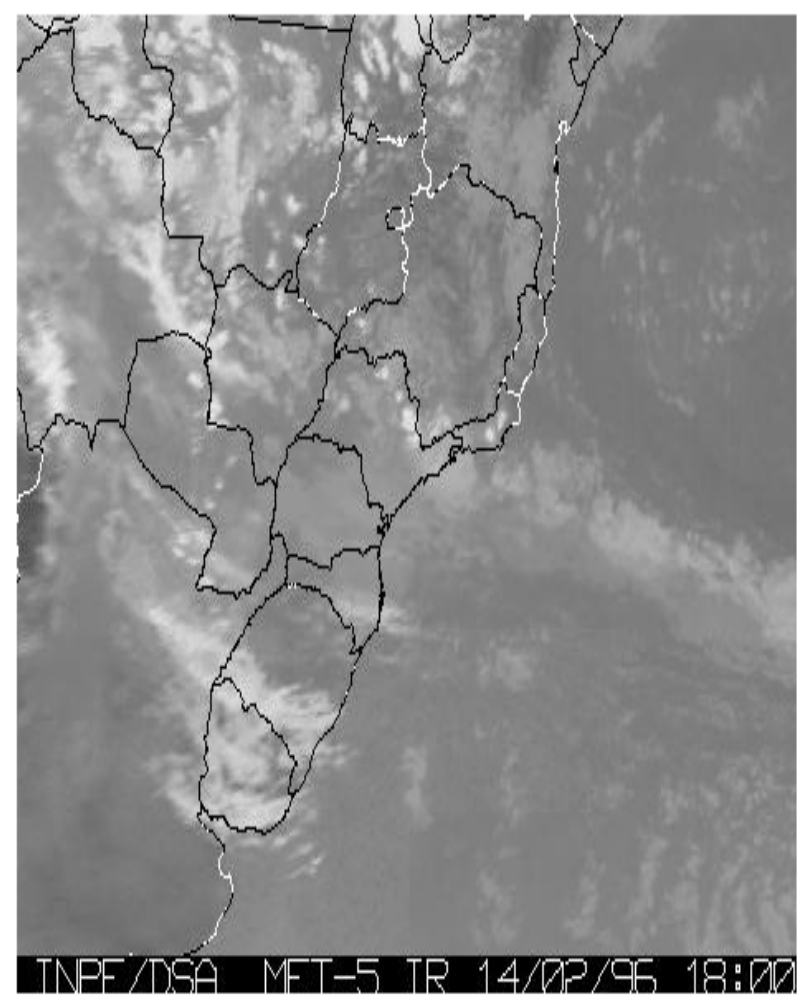

c)

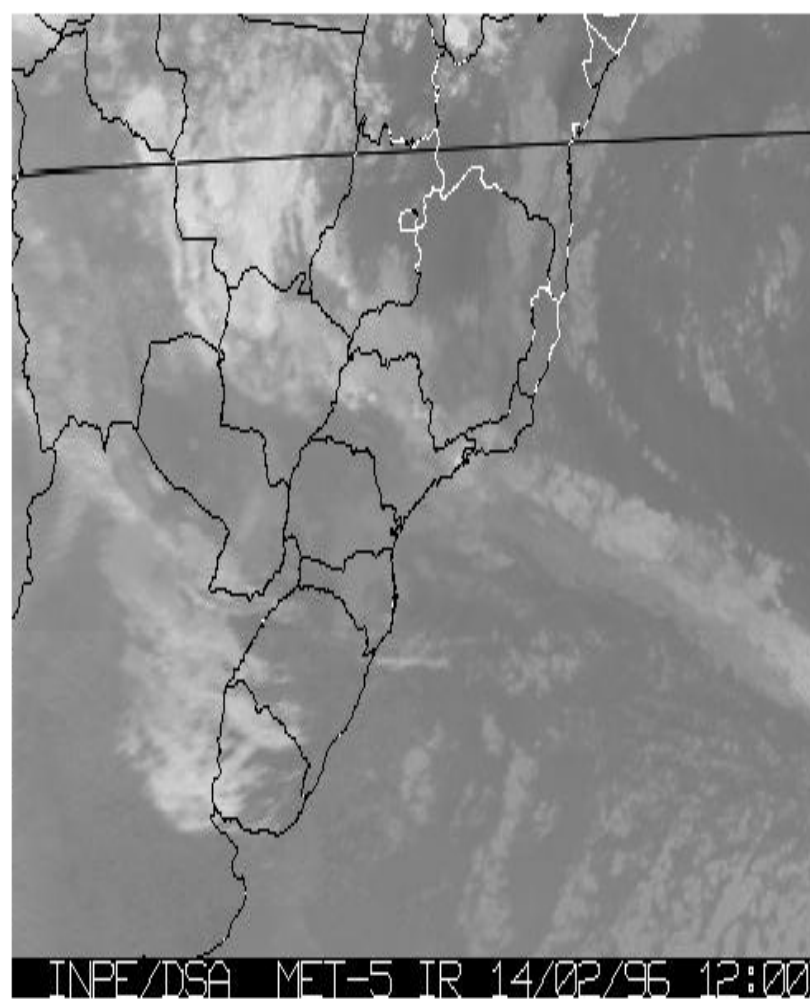

b)

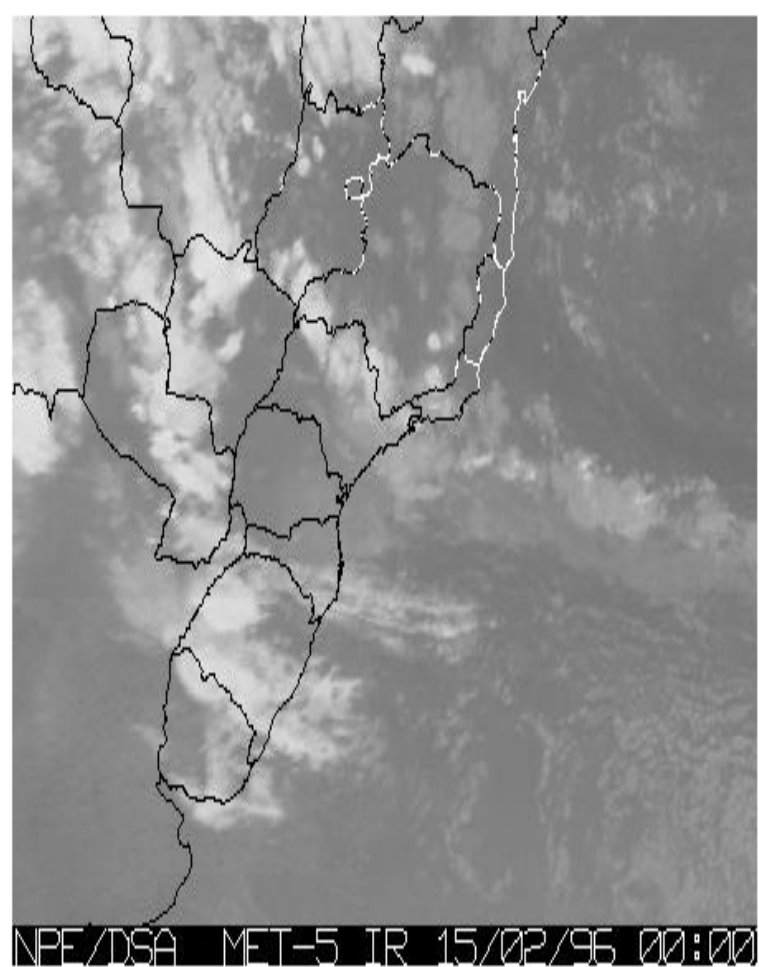

d)

Figura 13- Processo sinótico dos dias 14, 15 de fevereiro 1996 nas imagens dos satélites GOES-8 e METEOSAT-5. Figure 13- Synoptic process for 14, 15 February 1996 on GOES-8 images. 


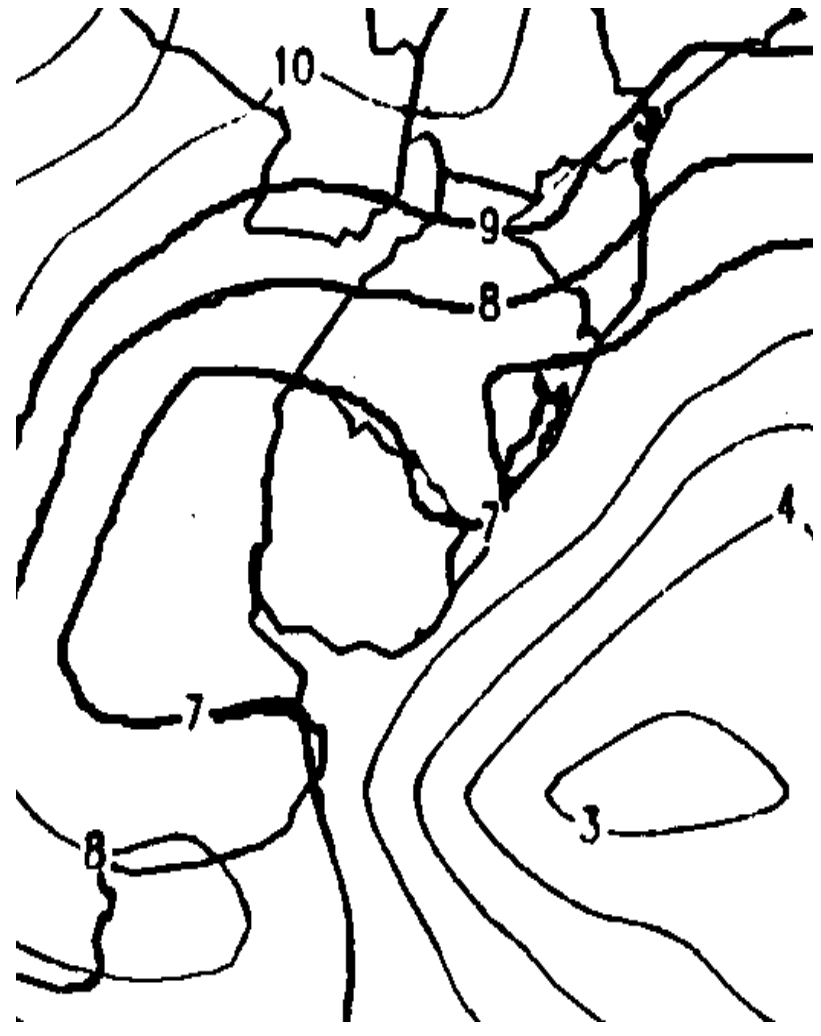

Figura 14- Mapa de temperatura do ar $\left({ }^{\circ} \mathrm{C}\right)$ no nível de 700 hPa do dia 15 de fevereiro de 1996.

Figure 14- Air temperature $\operatorname{map}\left({ }^{\circ} \mathrm{C}\right)$ at the level $700 \mathrm{hPa}$ for 15 February 1996.

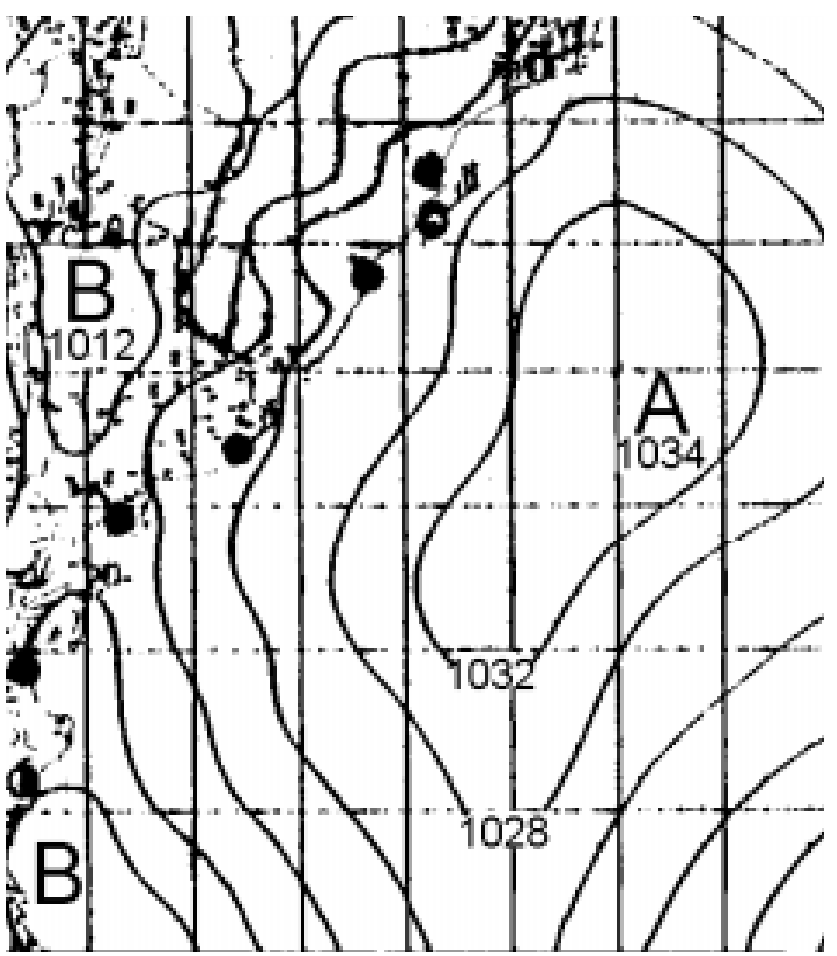

Figura 16- Mapa de pressão à superfície do dia 22 de setembro 1995.

Figure 16- Surface pressure map for 22 September 1995.

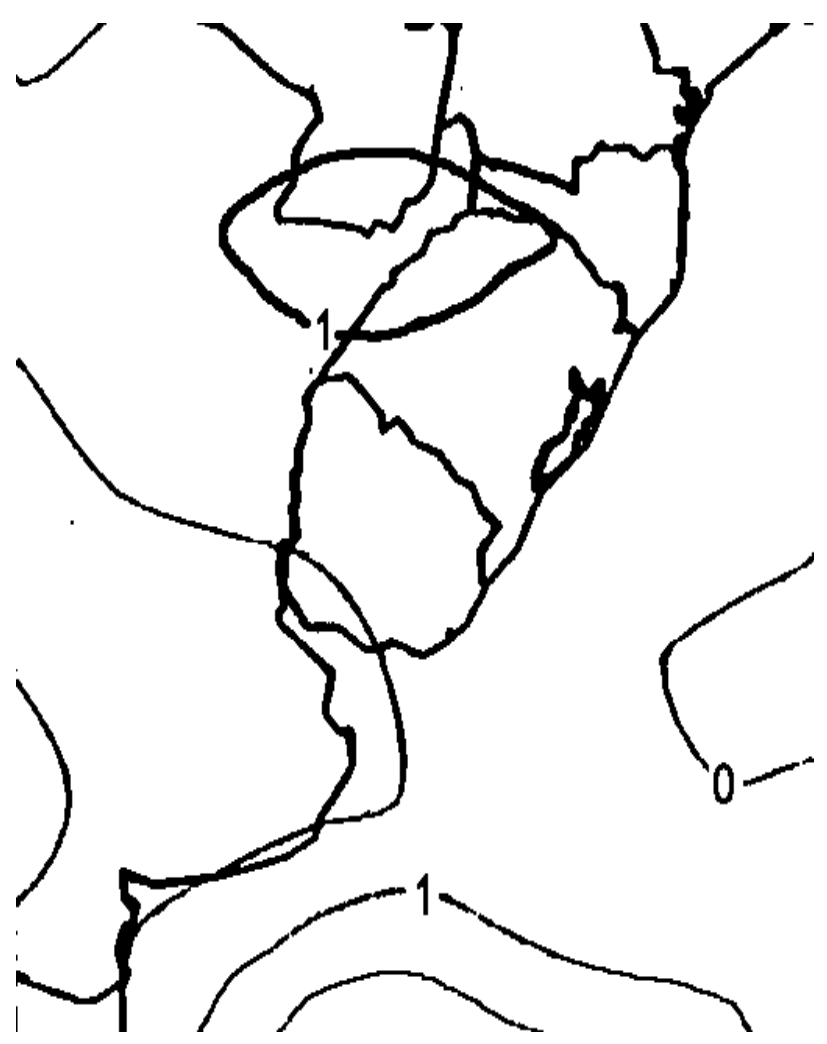

Figura 15- Mapa de advecção de temperatura do $\operatorname{ar}\left({ }^{\circ} \mathrm{C} / 12\right.$ horas) no nível de $700 \mathrm{hPa}$ do dia 15 de fevereiro de 1996.

Figure 15- Thermal advection map $\left({ }^{\circ} \mathrm{C} / 12\right.$ hours $)$ at the level 700 hPa for 15 February 1996.

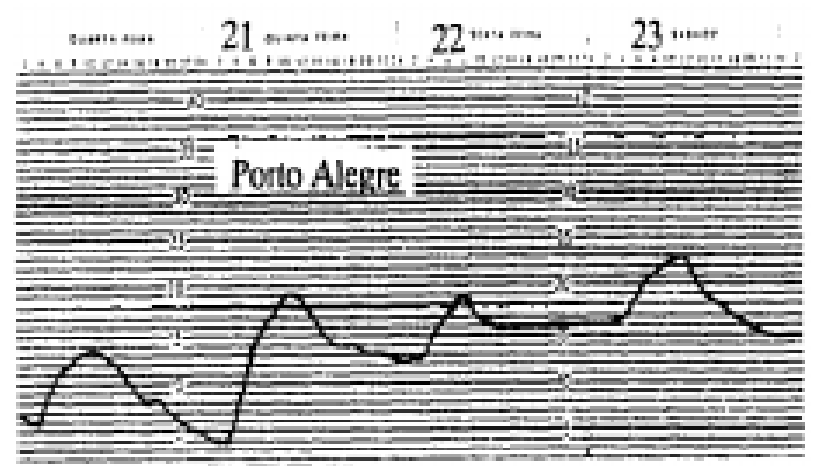

Figura 17- Gráficos da mudança de temperatura dos dias 22 e 23 de setembro de 1995.

Figure 17- Surface temperature variation for 22 and 23 September 1995. 


\section{Ciclogênese}

Neste tipo de processo, as imagens de satélites mostram uma massa de nuvens de curvatura anticiclônica ( às vezes duas ou três massas de nuvens com esta curvatura); nos mapas sinóticos localizam-se as periferias norte e noroeste do anticiclone e após 24 ou 48 horas, nesta massa de nuvens, pode formar-se o ciclone. Deve-se ressaltar que nessas situações a advecção de ar quente observada é muito intensa.

Apresenta-se abaixo um exemplo do processo descrito acima para o período de 22 a 23 de setembro de 1996 (Figs. 16 a 20 ).

Nestes dias, a massa de nuvens foi formada por duas massas de curvatura anticiclônica muito forte. Nesta região, em 22 de setembro, foi observada no mapa de pressão à superfície, a periferia oeste do anticiclone. Após $24 \mathrm{~h}$, desta massa formou-se o ciclone.

Os mapas de temperatura em $700 \mathrm{hPa}$ e os mapas de advecção apresentaram uma grande região com ar quente e com advecção de ar quente sobre a costa leste da Argentina e Oceano Atlântico. Sobre a superfície foi observada a elevação da temperatura: no período de 21 a 22 de setembro, a temperatura mínima em Pelotas aumentou em $11,8^{\circ} \mathrm{C}$ e a temperatura máxima em $1,4^{\circ} \mathrm{C}$.

\section{Relação entre a Curvatura da Massa de Nuvens e a Advecção de Ar Quente}

Como resultado desta pesquisa constatou-se que a advecção de ar quente é observada quando, na imagem de satélite, vê-se uma massa de nuvens de curvatura anticiclônica; a advecção de ar quente enfraquece ou termina quando diminui ou desaparece a curvatura anticiclônica.

Apresenta-se, como exemplo, a situação sinótica ocorrida no período de 28 a 29 de janeiro de 1996 (Fig. 21).

Em 28 de janeiro formou-se uma massa de nuvens de curvatura anticiclônica, e de 15 a 18 horas esta massa foi observada sobre o Paraguai, Rio Grande do Sul, Santa Catarina e noroeste da Argentina. Durante

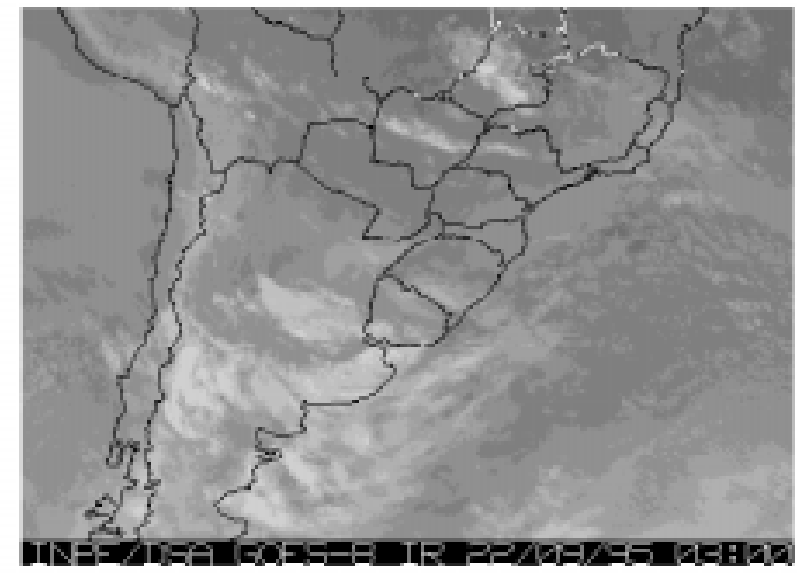

a)

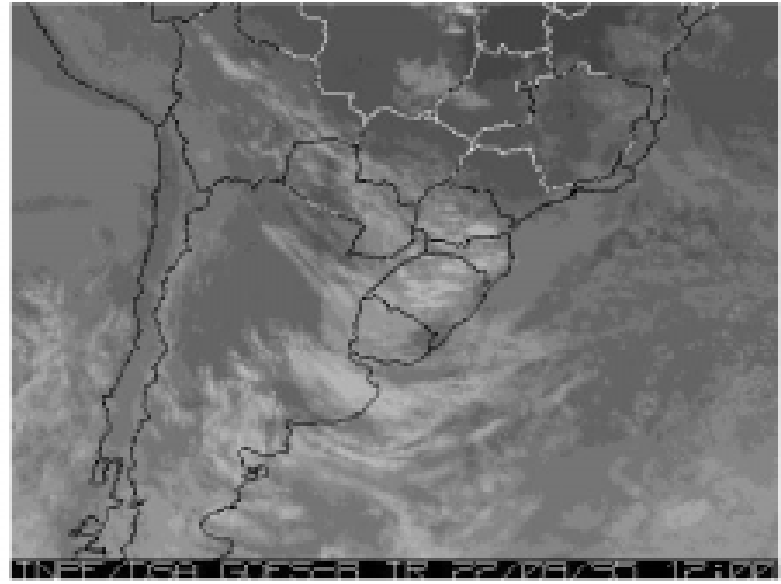

b)

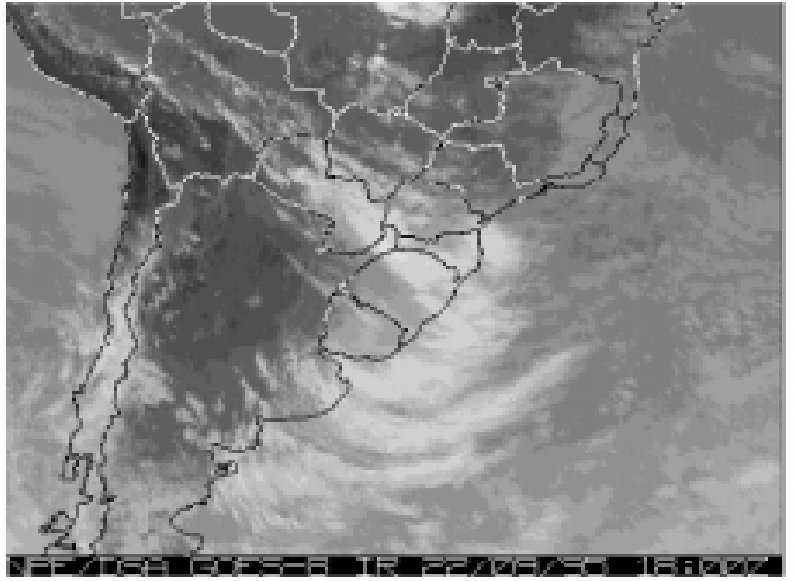

c)

Figure 18- Synoptic process for 22 September 1995 on GOES-8 images. 
o período de tempo das 15 horas às 21 horas, em 28 de janeiro, a curvatura anticiclônica da massa de nuvens aumentou na fronteira da mesma; no lado frio foi observada a corrente de jato. A curvatura anticiclônica começou a reduzir-se às 0 horas de 29 de janeiro; das 06 às 09 horas desapareceram as nuvens da corrente de jato; às 18 horas desapareceu a curvatura anticiclônica da massa de nuvens. Em 28 de janeiro a temperatura máxima à superfície aumentou até $30,2^{\circ} \mathrm{C}$ e foi $3,4^{\circ} \mathrm{C}$ maior que a temperatura do dia anterior. Também foi observada a interrupção da marcha normal da temperatura: às 20 horas de 28 de janeiro, a temperatura do ar parou de cair. Neste momento, a estação meteorológica ficou sob a parte central da massa de nuvens de curvatura anticiclônica.

Para as situações com advecção de ar quente no Hemisfério Sul, a curvatura da fronteira da massa de nuvens tem convexidade (abaulamento) na direção sul; no Hemisfério Norte, a convexidade é contrária, ou seja, em direção ao norte, ou a curvatura da fronteira da massa de nuvens nos dois Hemisférios é anticiclônica.

\section{CONCLUSÕES}

Os resultados desta pesquisa foram verificados durante cinco meses (abril a agosto 1996). Durante este período, foram observadas quatro situações com massa de nuvens com curvatura anticiclônica nas imagens dos satélites. Todas estas massas de nuvens estavam associadas com o aumento da temperatura; os aumentos máximo e mínimo da temperatura máxima foram de $13,8^{\circ} \mathrm{C}$ e $2,2^{\circ} \mathrm{C}$, respectivamente.

A análise dos dados de satélite e dados sinóticos

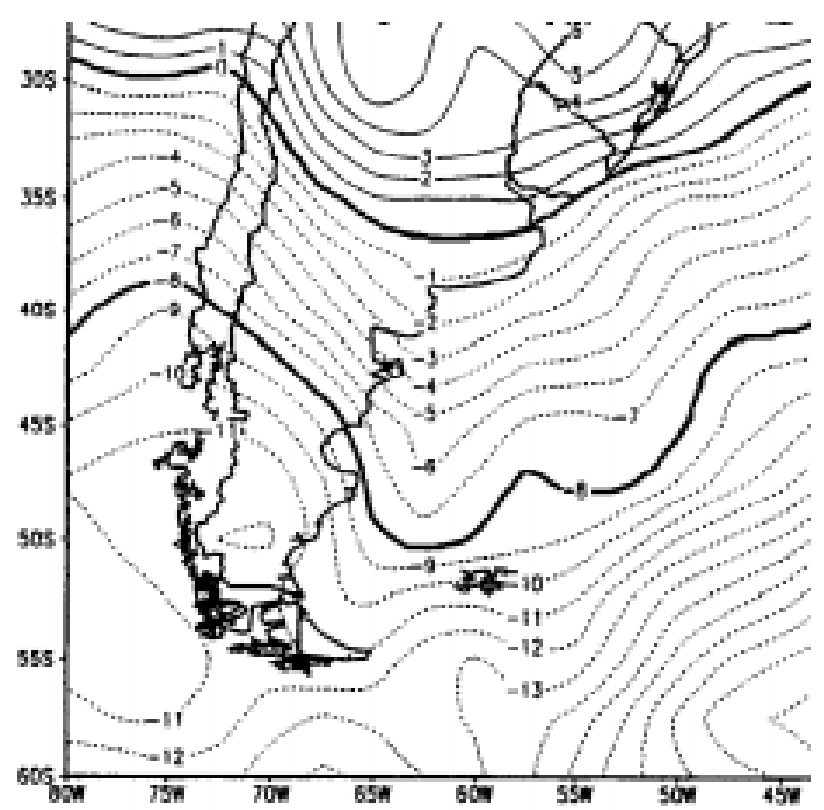

Figura 19- Mapa de temperatura do ar $\left({ }^{\circ} \mathrm{C}\right)$ no nível de 700 hPa do dia 22 de setembro de 1995.

Figure 19-Air temperature map $\left({ }^{\circ} \mathrm{C}\right)$ at the level $700 \mathrm{hPa}$ for convencionais mostra que as imagens de satélite permitem identificar as regiões com advecção de ar quente.

Foram obtidas as características dos sistemas de nuvens das regiões com advecção de ar quente, observadas nas imagens de satélite: curvatura anticiclônica e presença de maior quantidade de nuvens cirrus na fronteira da massa de nuvens.

Estes sistemas de nuvens são observados na periferia norte ou noroeste do anticiclone ou no campo de pressão difuso ou no cavado fraco; nos mapas sinóticos localiza-se uma linha de instabilidade. Em algumas situações, após 24 ou 48 horas, nesta massa de nuvens forma-se o ciclone e nos mapas sinóticos aparecem as frentes quente e fria. Em outras situações, o aparecimento da corrente de ar quente provoca a regeneração do ciclone e a intensificação da zona frontal.

Foi observado que a advecção de ar quente enfraqueceu ou terminou quando diminuiu ou desapareceu a curvatura anticiclônica.

A configuração dos principais tipos de sistemas de nuvens e processos sinóticos nas regiões com advecção de ar quente sobre a América do Sul foram obtidos a partir de informações de satélites.

Mostrou-se também que os dados de satélites permitem determinar as regiões com advecção de ar quente com maior antecedência ( em 24 - 48 horas) que os dados sinóticos. Isto é muito importante para a análise da situação sinótica, da zona frontal, das condições de frontogênese e, por isso, possibilitam uma melhor compreensão dos processos sinóticos e, principalmente, dão o suporte necessário às atividades

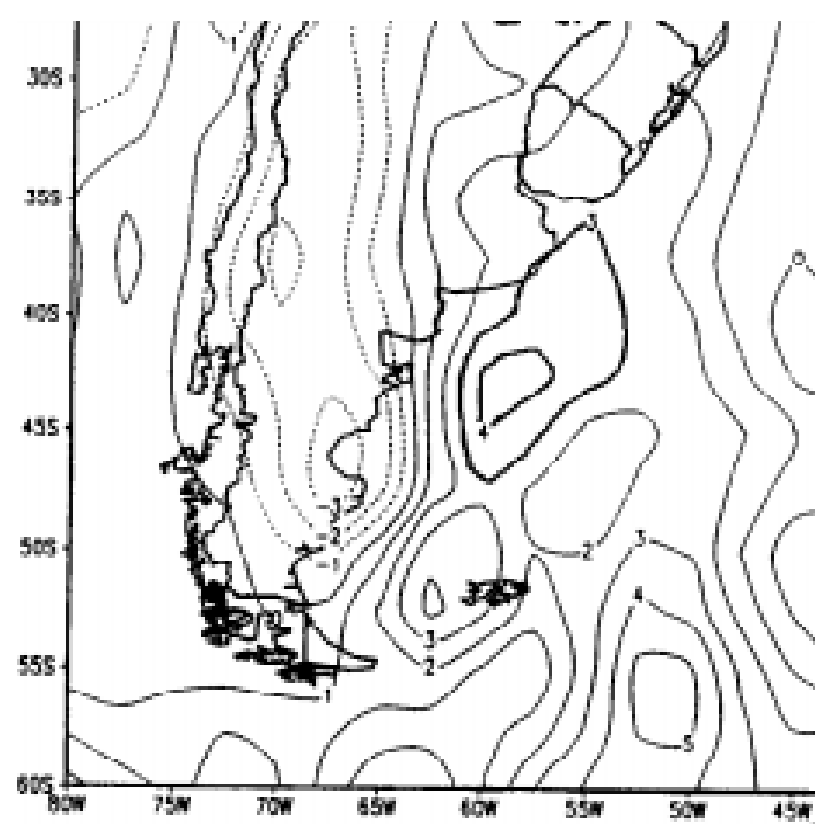

Figura 20- Mapa de advecção de temperatura do $\operatorname{ar}\left({ }^{\circ} \mathrm{C} / 12\right.$ horas $)$ no nível de $700 \mathrm{hPa}$ do dia 22 de setembro de 1995.

Figure 20-Thermal advection $\left({ }^{\circ} \mathrm{C} / 12\right.$ hours) at the level 700 


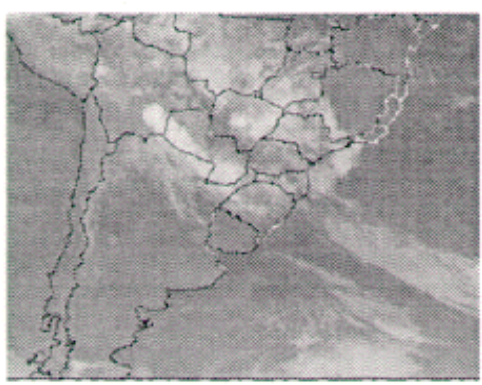

$01.2806 \mathrm{~h}$.

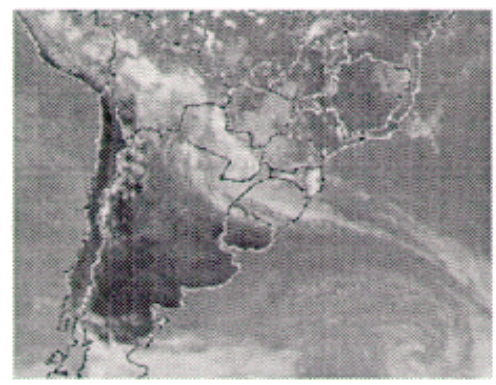

$01.2818 \mathrm{~h}$.

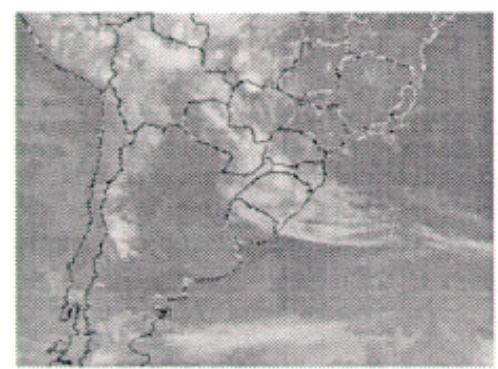

$01.2903 \mathrm{~h}$.

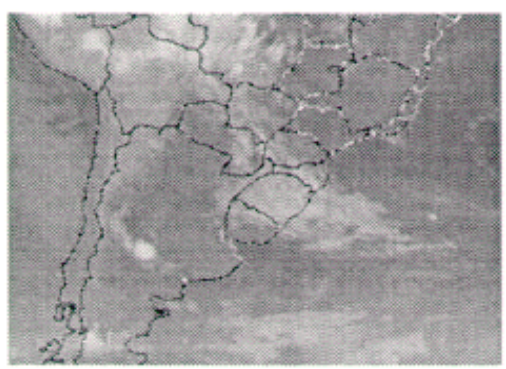

$01.2912 \mathrm{~h}$.

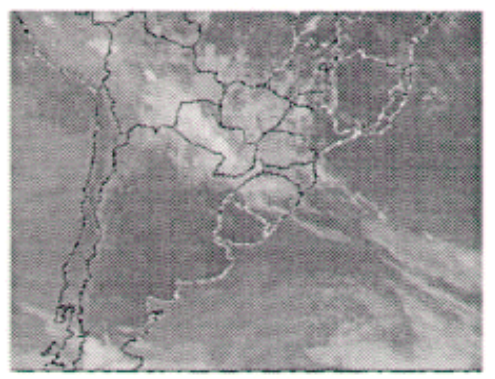

$01.2812 \mathrm{~h}$.

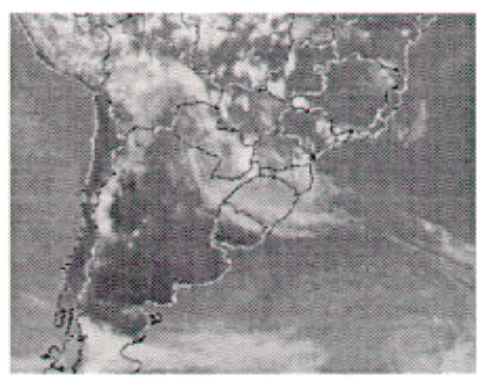

$01.2821 \mathrm{~h}$.

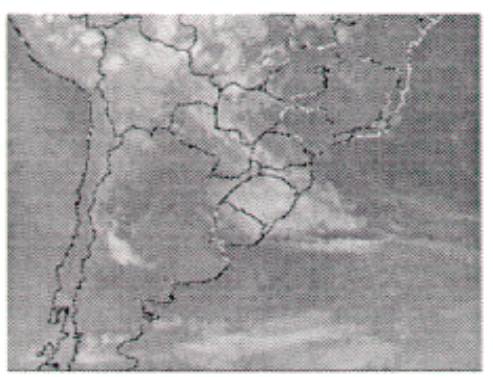

$01.2906 \mathrm{~h}$.

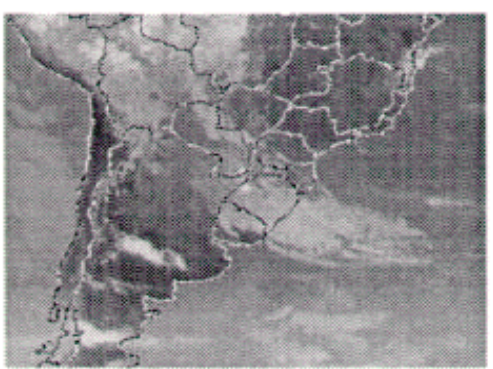

$01.2915 \mathrm{~h}$.

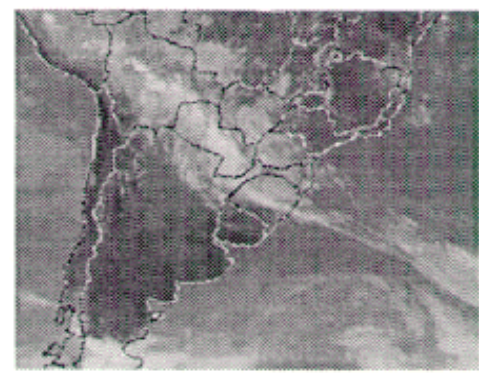

$01.2815 \mathrm{~h}$.

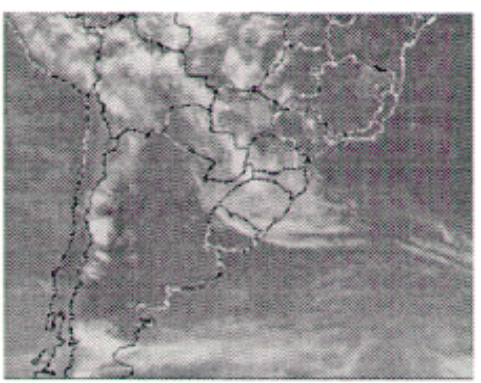

$01.2900 \mathrm{~h}$.

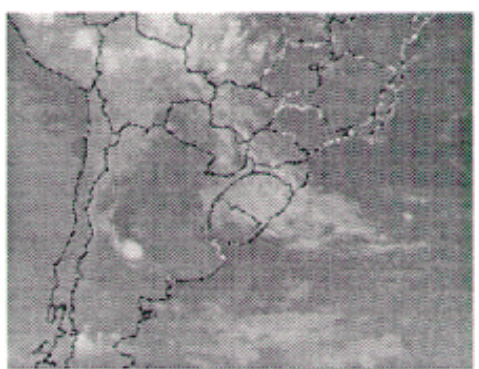

$01.2909 \mathrm{~h}$.

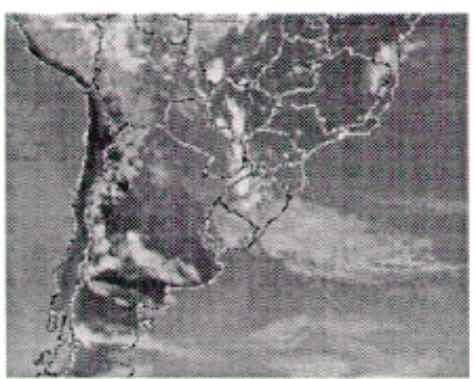

$01.2918 \mathrm{~h}$.

Figura 21- Processo sinótico dos dias 28, 29 de janeiro de 1996 nas imagens de satélite GOES-8.

Figure 21- Synoptic process for 28, 29 January 1996 on GOES-8 images. 
de previsão meteorológica operacional.

\section{AGRADECIMENTO}

Os autores agradecem a Profa. Maria Helena de Carvalho, do Departamento de Meteorologia da Universidade Federal de Pelotas, pela revisão final do artigo.

\section{REFERÊNCIAS}

BAKST, L. \& FEDOROVA, N. -1991- Analysis of satellite information for the purposes of short-term weather forecasting on the basis of personal computer. Issledovanie Zemli is Kosmosa. (in russian), 4: 8386.

BLUESTEIN, H. B. -1993- Synoptic-dynamic meteorology in midlatitudes. Volume II: observations and theory of weather systems. New York, Oxford University Press. 239-417.

CARLSON, T. N. -1980- Airflow through midlatitude cyclones and the comma cloud pattern. Mon. Weather Rev., 108 (10): 1498-1509.
CCOYLLO, O. R. S \& SILVA DIAS, P. L.-1996Penetração de ar frio na Amazônia Peruana. Anais do IX Congresso Brasileiro de Meteorologia, 1: 512-516, Campos do Jordão, SP.

FEDOROVA, N. \& BAKST, L. -1991- Use of information from geostationary satellite for routine analysis and short-term weather forecast. 8th. Meteosat Scientific User's Meeting. Proceedings. Norrkoping, Sweden, 307-315.

RAO, E. P. K., HOJMES, S. J., ANDERSON, R. K., WINSTON, J. S. \& LEHR, P. E. -1990- Weather Satellites: Systems, data and environmental applications. American Meteorological Society, Boston, 203-390.

VETLOV, I. \& VELTICHEV, N.-1982-Guide for investigation of satellite data in weather analysis and forecast. Chap. 4, 6, 7, 9, Leningrad, Gidreometeoisdat, (in russian) 60-119, 158-195, 209285.

\section{IDENTIFICATION OF WARM AIR ADVECTION ON SATELLITE DATA}

The paper presents a study of cloudiness having the typical structure: the anticyclonic curvature of the cloud's mass and a large quantity of Cirrus clouds on the cloudiness' border. The following data sources have been used in the present study: South America synoptic maps in the period of eight months during 1995-1996, temperature variation in meteorological stations and GOES- 8 infrared satellite images. Data in a period of five months of 1996 have been used for the verification of the results. The joint analysis of conventional and satellite data showed that this cloudiness structure is observed in synoptic situations with warm air advection. This cloudiness was localized in the northerly and northwesterly peripheries of the anticyclone, in the trough of the cyclone, or in the diffuse pressure field. It was generally presented as lines of the instability in the synoptic map. The temperature elevation is difficult to locate from conventional data in these situations. In some situations the cyclone was formed in the cloudiness with anticyclonic curvature; in other situations, warm air current caused the frontogenesis or the old cyclone regeneration. The temperature elevation in mesoscale regions corresponded to the mesoscale cloudiness with a typical structure. Warm air advection reduces or stops, if the anticyclonic curvature of cloud's mass decreases or disappears. The satellite data enabled the detection of the warm air advection regions earlier (24-48h) than the synoptic maps.

\section{NOTE ABOUT THE AUTHORS}

\section{Natalia Fedorava}

Formado em Meteorologia (1971) e Mestre em Meteorologia (1973) pela Universidade Federal de Moscou, Rússia, Ph. D. em Meteorologia (1980 pelo Centro Hidrometeorológico da Rússia, Moscou. Pesquisador Senior (1973-1994) do Centro Hidrometeorológico da Rússia, Moscou, a partir de 1995 é Professor Adjunto da UFPel. Possui dois livros, 30 capítulos de livros publicados, mais de trinta artigos publicados em periódicos científicos nacionais e internacionais. Área de especialização é Meteorologia Sinótica e Meteorologia Sinótica por Satélite.

\section{Leonid Bakst.}

M. Sc. (Computers) em 1972 e Ph. D. (Cybernetic) 1980 pela Moscow Electronic Machine Building Institute, Rússia. Engenheiro Eletrônico Senior do Centro de Computação Principal (1972-1987), Pesquisador do Centro Hidrometeorológico da Rússia (1988-1993), Chefe de Departamento de Serviços Operacionais de Informações de Satélite, Centro Hidrometeorológico da Rússia (1994-1995). Atualmente é Professor Visitante no UFPel, a partir de 1995. Áreas de pesquisa incluem processamento de dados de satélite e análise de imagens. 